\title{
Role of Endoscopic Ultrasonography in Guiding Treatment Plans for Upper Gastrointestinal Subepithelial Tumors
}

\author{
Jeong Seop Moon \\ Dpartment of Internal Medicine, Inje University Seoul Paik Hospital, Inje University College of Medicine, Seoul, Korea
}

Gastrointestinal (GI) subepithelial tumors (SETs) are usually observed incidentally by endoscopy and have diverse prognoses, varying from benign to potentially malignant. When a GI SET is suspected, endoscopic ultrasonography (EUS) is the most accurate diagnostic method to differentiate it from extraluminal compression. To determine the nature of GI SETs, EUS is also the most accurate diagnostic method, and reveals the precise sonographic nature of the lesion. There are some SETs with typical EUS findings of GI SETs, but most hypoechoic lesions are difficult to diagnose based on EUS images alone. EUS is also helpful to determine GI wall involvement in SETs and optimal treatment methods. For the diagnosis of GI SETs, obtaining a proper specimen is essential. EUS-guided cytology or biopsy methods such as fine-needle aspiration, Tru-Cut biopsy, and the newly introduced fine-needle biopsy (FNB) provide good results. To increase the diagnostic yield for GI SETs, cytology with immunocytochemical staining is used for cytological interpretation, resulting in good diagnostic yields. Recently, EUS-FNB using cheese slicer technology has been introduced, and has been reported to provide good diagnostic results for GI SETs. Clin Endosc 2016;49:220-225

Key Words: Endoscopic ultrasound; Gastrointestinal tract; Subepithelial tumor

\section{INTRODUCTION}

Many advances in the diagnosis and management of upper gastrointestinal (GI) subepithelial tumors (SETs) have been seen. Usually, GI SETs are observed incidentally by endoscopy. There are many types of GI SET, which have prognoses varying from benign to very aggressive with malignant potential. Therefore, proper diagnostic and therapeutic plans are needed for GI SETs. When a GI SET is suspected, the first diagnostic step is to differentiate it from extraluminal compression. For this purpose, endoscopic ultrasonography (EUS) is the most accurate diagnostic method. ${ }^{1}$ If extraluminal compression

\footnotetext{
Received: March 10, 2016 Revised: May 10, 2016

Accepted: May 11, 2016

Correspondence: Jeong Seop Moon

Department of Internal Medicine, Inje University Seoul Paik Hospital, Inje University College of Medicine, 9 Mareunnae-ro, Jung-gu, Seoul 04551, Korea Tel: +82-2-2270-0012, Fax: +82-2-2279-4021, E-mail: moonjs2@unitel.co.kr

(cc) This is an Open Access article distributed under the terms of the Creative Commons Attribution Non-Commercial License (http://creativecommons.org/ licenses/by-nc/3.0) which permits unrestricted non-commercial use, distribution, and reproduction in any medium, provided the original work is properly cited.
}

is ruled out, the next diagnostic step is to determine the nature of the lesion. EUS is also the most accurate method for achieving this. EUS can reveal the sonographic nature of GI SETs, such as the originating layer, size, border, echogenic homogeneity, and the presence of echogenic and anechoic foci. ${ }^{2}$ There are some typical findings for some GI SETs such as lipoma, duplication cysts, and ectopic pancreas. ${ }^{2,3}$ However, most hypoechoic subepithelial lesions are difficult to diagnose using EUS images alone. Biopsy is necessary for the definite diagnosis of GI SETs. However, obtaining appropriate biopsy specimens using an endoscopic biopsy procedure is difficult, and bleeding is a frequent complication when using the biteon-bite biopsy technique. ${ }^{4}$ Several modified endoscopic biopsy methods for GI SETs have been introduced, but the results of these methods are inconclusive. ${ }^{5}$ To overcome the limitations of conventional endoscopic biopsy methods, EUS-guided cytology or biopsy methods, such as EUS-guided fine-needle aspiration (EUS-FNA), EUS-guided Tru-Cut biopsy (EUSTCB), and recently, EUS-guided fine-needle biopsy (EUSFNB) technique, have been introduced. Sufficient tissue is indispensable for the diagnosis of GI SETs. For this purpose, 
EUS-TCB is an ideal EUS procedure, but it has limited diagnostic value and is associated with technical difficulties, especially when the lesion is located in the duodenum. EUS-FNA is a safe procedure for the diagnosis of GI SETs, but is mainly used for cytological studies. Cells can be observed readily, but not the complete tissue required for the diagnosis of GI SETs. Therefore, immunohistochemical staining (IHS) methods are used for interpreting samples obtained using EUS-FNA, resulting in good diagnostic yields. Recently, EUS-FNB using cheese slicer technology has been introduced, and reportedly provides good results for the diagnosis of GI SETs. ${ }^{6}$

\section{ROLE OF RADIAL EUS IN GI SET DIAGNOSIS}

A recent survey revealed that $94.9 \%$ of South Korean endoscopists had a positive opinion toward EUS for SETs. ${ }^{7}$ The barriers to performing EUS were a lack of experienced endosonographers among $66.2 \%$ of survey responders. ${ }^{7}$

\section{Differential diagnosis of SETs}

Radial EUS can reveal the precise nature of GI SETs. SETs such as lipoma, duplication cysts, and ectopic pancreas have some typical findings (Table 1). GI SETs without malignant potential can be periodically followed-up by endoscopy or EUS, but EUS findings are not sufficient to differentiate some mesenchymal cell tumors from each other. Using EUS findings, it is possible to diagnose malignant SETs with a sensitivity of $64 \%$ and a specificity of $80 \% .{ }^{4}$ All gastrointestinal stromal tumors (GISTs) have some malignant potential. By assessing the echogenicity of lesions, we can differentiate GISTs, leiomyomas, and schwannomas. The echogenicity of a leiomyoma is equal to the echogenicity of proper muscle, while a GIST showed slightly higher echogenicity than that of the proper muscle, and a schwannoma showed extremely low echogenicity. ${ }^{2}$ EUS findings suggestive of high-grade malignancy in gastric GISTs are (1) greater size, and the presence of (2) lobulated forms, (3) irregular borders, and (4) echogenic foci in SETs. However, EUS findings are not sufficient to accurately predict malignancy. ${ }^{8}$ Interobserver variation in the interpretation of EUS samples is a key factor explaining discrepancies between results. Several scoring system criteria for predicting gastric subepithelial lesions have introduced. The four variables used are location, originating layer, echogenicity, and the shape of tumors. ${ }^{9}$

Table 1. Differential Diagnosis of Subepithelial Tumors by Endoscopic Ultrasonography Features

\begin{tabular}{|c|c|c|}
\hline Subepithelial tumors & Wall layer of origin & Echogenicity with findings \\
\hline \multicolumn{3}{|l|}{ Benign } \\
\hline Leiomyoma & 2 or 4 & Hypoechoic, round or oval, well demarcated \\
\hline Neural origin tumors & 3 or 4 & Hypoechoic, round or oval, well demarcated \\
\hline \multicolumn{3}{|l|}{ Schwannoma } \\
\hline \multicolumn{3}{|l|}{ Neuroma } \\
\hline \multicolumn{3}{|l|}{ Neurofibroma } \\
\hline Lipoma & 3 & Intensely hyperechoic, smooth margin \\
\hline Lymphangioma & 3 & Anechoic \\
\hline Cyst & 3 & Anechoic, compressible \\
\hline Duplication cyst & Any or extramural & Anechoic \\
\hline Ectopic pancreas & 2 or 3 & Hypoechoic, heterogeneous, ductal structure \\
\hline Inflammatory fibroid polyp & 2 or 3 & Hypoechoic, homogenous or mixed \\
\hline Granular cell tumor & 2 or 3 & Hypoechoic, oval, small (thickness $<1 \mathrm{~cm}$ ) \\
\hline Varices & 2 or 3 & Anechoic, serpiginous or linear \\
\hline \multicolumn{3}{|l|}{ Malignant/malignant potential } \\
\hline Gastrointestinal stromal tumor & 4 (rarely 2 or 3 ) & Hypoechoic \\
\hline Lymphoma & 2,3, or 4 & Hypoechoic \\
\hline Carcinoid & 2 or 3 & Hypoechoic \\
\hline Metastatic carcinoma & Any & Hypoechoic \\
\hline Glomus tumor & 3 or 4 & Hypoechoic, heterogeneous, irregular margin \\
\hline
\end{tabular}




\section{EUS follow-up for SETs}

Follow-up EUS is often used in SETs smaller than $2 \mathrm{~cm}$. Tumor growth during follow-up is a major indicator of malignant potential. For small GI SETs, follow-up after a 1-year interval is recommended. If the size of the mass is unchanged during two serial EUS follow-ups, extended follow-up is suggested. ${ }^{9}$ The American Gastroenterological Association Institute Technical Review recommended follow-up by EUS or endoscopy at regular intervals for gastric SETs smaller than $3 \mathrm{~cm}$ in 2006. ${ }^{10}$ However, the National Comprehensive Cancer Network recommended surgical resection of GISTs larger than $2 \mathrm{~cm}$ because of their malignant potential in 2010. ${ }^{11}$

\section{Role of radial EUS before removal of SETs}

Before removing SETs, the method of removal needs to be determined based on the size, location, and originating layer in the GI tract wall. Lesions involving the mucosa and submucosa can be removed completely and safely with endoscopic mucosal resection or endoscopic submucosal dissection (ESD). Lesions involving the muscularis propria are usually removed surgically because the complete endoscopic resection of these lesions is associated with the risk of perforation. EUS is indispensible for determining GI wall layer involvement and treatment methods. ${ }^{12}$ Hwang et al. ${ }^{13}$ reported the endoscopic resection of gastric SETs from the muscularis propria (well margined, endoluminal growth, 2 to $5 \mathrm{~cm}$ in size), resulting in complete endoscopic resection in $64 \%$ of cases. The resection rate of SETs with underlying muscle layers in EUS was $93.8 \%$.
However, the resection rate of SETs without any underlying muscle layers in EUS was $11.1 \% .^{13}$ These results mean that the complete resection of SETs from the muscularis propria was more possible when the underlying muscle layer was visible under the SETs. Furthermore, perforation often developed in cases of tumors without underlying muscle layers in EUS. ${ }^{13}$ Białek et al. ${ }^{14}$ reported that EUS determined the originating layer of the tumor in $73 \%$ of cases before ESD for gastric SETs. In SETs originating from the muscularis propria, the lesions were resected at the level of the muscularis propria when connected to the muscularis propria by thin muscle fibers or a muscular stalk. However, the complete resection of SETs was not possible when there was a tight connection between the lesion and the muscularis propria covering a large area. The en bloc complete resection rates were $68 \%$ and $100 \%$ for tumors with and without connections to the muscularis propria, respectively. ${ }^{14}$

\section{ROLE OF EUS-FNA IN DIAGNOSING GI SETs}

\section{Diagnostic accuracy}

Tissue acquisition by EUS-FNA is the best choice in the study of SETs, especially those originated from the 4th EUS layer. Obtaining sufficient tissue is necessary for diagnosis using IHS. A large amount of data concerning the use of EUS-FNA in the diagnosis of GI SETs has been published

Table 2. Results of EUS-FNA in SETs

\begin{tabular}{|c|c|c|c|c|c|}
\hline Study & $\begin{array}{l}\text { No. of } \\
\text { patients }\end{array}$ & Study design & $\begin{array}{l}\text { Indication for } \\
\text { EUS-FNA }\end{array}$ & $\begin{array}{l}\text { Average pass } \\
(\min -\mathbf{m a x})\end{array}$ & Results \\
\hline $\begin{array}{l}\text { Ando et al. } \\
(2002)^{15}\end{array}$ & 23 & Retrospective & GIST & $2.83(1-5)$ & Accuracy for diagnosis of malignant GIST 91\% \\
\hline $\begin{array}{l}\text { Akahoshi et } \\
\text { al. }(2007)^{20}\end{array}$ & 51 & Prospective & PM origin SET & $2.4(1-6)$ & $\begin{array}{l}\text { Adequate specimen } 82 \% \text { using Olympus needle } \\
\text { (NA-11J-KB; Olympus Medical Systems) } \\
\text { Diagnostic rate: } 71 \%(<2 \mathrm{~cm}), 86 \%(2-4 \mathrm{~cm}), 100 \% \\
\quad(>4 \mathrm{~cm}) \\
\text { Sensitivity } 100 \% \text {, specificity } 80 \% \text {, PPV } 96 \% \text {, NPV } \\
\quad 100 \%\end{array}$ \\
\hline $\begin{array}{l}\text { Hoda et al. } \\
(2009)^{16}\end{array}$ & 112 & Retrospective & PM origin SET & $5.3(3-9)$ & $\begin{array}{l}\text { Diagnostic yield } 83.9 \% \text { (diagnostic } 61.6 \% \text {, suspicious } \\
22.3 \% \text { ) }\end{array}$ \\
\hline $\begin{array}{l}\text { Sepe et al. } \\
(2009)^{17}\end{array}$ & 37 & Retrospective & GIST & $\begin{array}{l}\text { Not mentioned } \\
\quad(1-7)\end{array}$ & Sensitivity for GIST diagnosis $78.4 \%$ \\
\hline $\begin{array}{l}\text { Mekky et al. } \\
(2010)^{18}\end{array}$ & 141 & Retrospective & SET in stomach & Not mentioned & $\begin{array}{l}\text { Adequate specimen } 83 \% \\
\text { Diagnostic yield } 82.3 \% \text { (diagnostic } 43.3 \% \text {, suspicious } \\
39 \% \text { ) }\end{array}$ \\
\hline $\begin{array}{l}\text { Suzuki et al. } \\
(2011)^{19}\end{array}$ & 47 & Retrospective & PM origin SET & Not mentioned & $\begin{array}{l}\text { Adequate specimen } 74.5 \% \\
\text { Diagnostic yield } 74.5 \%\end{array}$ \\
\hline
\end{tabular}

EUS-FNA, endoscopic ultrasonography-guided fine-needle aspiration; SET, subepithelial tumor; min-max, minimum-maximum; GIST, gastrointestinal stromal tumor; PM, proper muscle; PPV, positive predictive value; NPV, negative predictive value. 
(Table 2). The diagnostic accuracy rate of EUS-FNA is reported as $60 \%$ to $80 \%$ for GI SETs. ${ }^{1}$ Most studies of EUSFNA for the diagnosis of SETs were retrospective in nature. e $^{15-19}$ A prospective study using 22 gauge $(G)$ power-shot needles (NA-11J-KB; Olympus Medical Systems, Tokyo, Japan) by Akahoshi et al. ${ }^{20}$ reported a puncture success rate of $100 \%$, an adequate specimen acquisition rate of $82 \%$, and a diagnostic rate of $82 \%$. Forward-viewing linear EUS has been introduced, and has been shown to provide good image quality and shorter observation times in SETs than oblique-viewing linear EUS. ${ }^{21}$ EUS-FNA for SETs using a forward-viewing linear EUS has provided good results: full histologic assessment rate of $93.4 \%$, sensitivity of $92.8 \%$, specificity of $100 \%$, positive likelihood ratio infinity, and negative likelihood ratio $0.07 \%$ for distinguishing neoplastic and non-neoplastic diseases. ${ }^{22}$ However, a European study using 19 G EUS-FNA needles in gastric SETs provided a feasibility of only $46 \%$ and a diagnostic yield of $52 \%{ }^{23}$ Mekky et al. ${ }^{18}$ reported results of EUS-FNA in the diagnosis of gastric SETs. In that study, an average of 2.5 EUS-FNA passes was performed, yielding an adequate sample in $83 \%$ of cases. The sample allowed diagnosis in $43.3 \%$ of cases, while the sample was suggestive in $39 \%$ of cases and was non-diagnostic in $17.7 \%$ of cases. Sepe et al. ${ }^{17}$ reported a sensitivity of $78.4 \%$ for EUS-FNA for GISTs.

\section{Factors associated with good EUS-FNA results}

\section{Size and location of SETs}

Tumor size and location are important factors for good sampling in EUS-FNA for GI SETs. The diagnostic rate for tumors $\geq 4 \mathrm{~cm}$ was $100 \%$, but for tumors of 2 to $4 \mathrm{~cm}$ and $<2$ $\mathrm{cm}$, the diagnostic rates were only $86 \%$ and $71 \%$, respective$\mathrm{ly}^{20}$ Another paper provided interesting results, and suggested that the sensitivity of EUS-FNA cytology was $0 \%(0 / 4)$ in GISTs $>10 \mathrm{~cm}$ and $100 \%$ in GISTs of 5 to $10 \mathrm{~cm}$, suggesting that the necrosis associated with larger tumors decreased the diagnostic yield. ${ }^{17}$ Tumors located in the lower third of the stomach and in patients $<60$ years old were difficult to obtain adequate gastric SET samples from. ${ }^{19}$

\section{Immunohistochemical staining}

In GI SETs and especially in suspected GISTs, obtaining sufficient tissue is important for diagnosis. In EUS-FNA, the specimen is processed with cell blocking and IHS using a C-KIT in addition to cytology. ${ }^{11}$ Differentially diagnosing GISTs from other mesenchymal tumors is not easy using cytology alone. Findings of mitosis in EUS-FNA specimens are known to be associated with malignant GISTs. ${ }^{15} \mathrm{Ki}-67$ staining is helpful in evaluating the aggressiveness of GISTs, and every malignant GIST shows Ki-67 labeling indices
$>3 \%{ }^{2,15}$ However, discrepancies in Ki-67 staining results have been reported between EUS-FNA specimens and resected specimens, and are probably due to intra- or interlobular heterogeneity.

\section{EUS-FNA needle tissue sampling}

Many studies have reported the use of various EUS-FNA needles to improve diagnostic accuracy. Diagnosis using 19 G EUS-FNA needles was expected to yield better results than those obtained using 22 or $25 \mathrm{G}$ needles. Tissue sampling and diagnostic rates for SETs were similar between 22 and 25 G EUS-FNA needles (sampling rate, sensitivity, positive predictive value, negative predictive value: $100 \%$, $55 \%, 100 \%$, and $0 \%$ for $22 \mathrm{G}$ needles; $100 \%, 64 \%, 100 \%$, and $0 \%$ for $25 \mathrm{G}$ needles). ${ }^{25}$ Furthermore, $25 \mathrm{G}$ needles were superior to $22 \mathrm{G}$ needles for diagnosing mobile small lesions. Data obtained using 19 G EUS-FNA needles made of nitinol resulted in good tissue acquisition, adequate for cytologic assessment in $100 \%$ of cases with a $100 \%$ rate of technical success, including when the transduodenal route was used. A histologic yield of $95 \%$ using this needle was similar to the 90\% achieved in EUS-FNB using 19 G Pro-Core (Cook Endoscopy, Wilson-Salem, NC, USA) needles. ${ }^{26}$ In GI SETs, diagnostic accuracy increases with needle passes of EUS-FNA, reaching a plateau after several passes. The number of passes required to reach a plateau has been reported as $2.5^{18}$ to $4 .^{27}$

\section{On-site cytopathologist}

The presence of an on-site cytopathologist during EUSFNA procedures increases the sensitivity of EUS-FNA. ${ }^{24,27}$ EUS-FNA with an on-site cytopathologist (rapid on-site cytopathological examination) resulted in a $10 \%$ to $29 \%$ increase in the adequacy rates of EUS-FNA specimens and a $10 \%$ to $15 \%$ increase in the diagnostic rate. ${ }^{27,28}$ Recently, macroscopic on-site quality evaluation (MOSE) for EUS specimens without a cytopathologist was introduced. ${ }^{29}$ In this previous study, a macroscopic visible core $>4 \mathrm{~mm}$ on MOSE was considered to be an indicator of specimen quality. ${ }^{29}$

\section{EUS-TCB}

EUS-TCB was introduced to allow core tissue to be obtained, but was found to present technical difficulties associated with needle stiffness. EUS-TCB is particularly useful when complete histological structures and IHS were needed. ${ }^{28}$ Specimens from EUS-TCB increase diagnostic accuracy in cases of gastric submucosal masses, pancreatic masses, lymphoma, and necrotic tumors compared to EUS-FNA. ${ }^{28}$ The results of EUS-TCB are affected by tumor location and size in the case of gastric SETs. ${ }^{30}$ Gastric SETs $<3 \mathrm{~cm}$ provide less sufficient samples than tumors $>5 \mathrm{~cm}$. In gastric SETs, 
the yield of EUS-TCB by location was $60 \%$ in the cardia, $50 \%$ in the fundus, $60 \%$ in the body, and $25 \%$ in the antrum. ${ }^{30}$ IHS is very important for differentiating malignant from benign SETs. EUS-TCB is very helpful in IHS, and the IHS staining yield of EUS-TCB is approximately $80 \%$ to $90 \%{ }^{30}$

\section{EUS-FNB}

Recently EUS-FNB was introduced using reverse bevel cheese slicer technology. ${ }^{31}$ A Korean EUS study group compared 22 G EUS-FNA and 22 G EUS-FNB in EUS-guided GI SET sampling. The EUS-FNB group required a significant lower number of needle passes than the EUS-FNA group ( 4 vs. $2, p=0.025$ ). The EUS-FNB group had higher yields of optimal macroscopic (30\% vs. $92 \%, p=0.006$ ) and histological ( $20 \%$ vs. $75 \%, p=0.010)$ core samples with three needle passes, which resulted in a high diagnostic rate ( $20 \%$ vs. $75 \%$, $p=0.010)^{6}$

\section{CONCLUSIONS}

Radial and linear EUS play important roles in the diagnosis and treatment of GI SETs. When SETs are suspected based on endoscopy, typical GI SETs can often be diagnosed using radial EUS findings. Radial EUS is also essential for determining the GI wall involvement of SETs and for guiding the treatment plan in cases of upper GI SETs. EUS-FNA is a good method for tissue diagnosis when a GI SET is suspected. Cytological examination with IHS is essential for the best diagnostic performance in GI SETs. EUS-TCB is good for tissue acquisition, but is associated with some technical challenges. The development of new EUS-FNB needles promises better GI SET diagnosis rates, but due to some technical challenges, the best method for EUS-guided tissue diagnosis in SETs remains to be confirmed.

\section{Conflicts of Interest}

The author has no financial conflicts of interest.

\section{REFERENCES}

1. Moon JS. Endoscopic ultrasound-guided fine needle aspiration in submucosal lesion. Clin Endosc 2012;45:117-123.

2. Sakamoto H, Kitano M, Kudo M. Diagnosis of subepithelial tumors in the upper gastrointestinal tract by endoscopic ultrasonography. World J Radiol 2010;2:289-297.

3. Landi B, Palazzo L. The role of endosonography in submucosal tumours. Best Pract Res Clin Gastroenterol 2009;23:679-701.

4. Ji JS, Lee BI, Choi KY, et al. Diagnostic yield of tissue sampling using a bite-on-bite technique for incidental subepithelial lesions. Korean J Intern Med 2009;24:101-105.

5. Tae HJ, Lee HL, Lee KN, et al. Deep biopsy via endoscopic submucosal dissection in upper gastrointestinal subepithelial tumors: a prospective study. Endoscopy 2014;46:845-850.

6. Kim GH, Cho YK, Kim EY, et al. Comparison of 22-gauge aspiration needle with 22-gauge biopsy needle in endoscopic ultrasonography-guided subepithelial tumor sampling. Scand J Gastroenterol 2014;49:347-354.

7. Lee TH, Kim EY, Kim JO, Lee KH, Lee JS; Korean EUS Study Group. South Korean endoscopists' attitudes toward endoscopic ultrasound for the evaluation of gastrointestinal diseases. Turk J Gastroenterol 2014;25:63-69.

8. Okubo K, Yamao K, Nakamura T, et al. Endoscopic ultrasound-guided fine-needle aspiration biopsy for the diagnosis of gastrointestinal stromal tumors in the stomach. J Gastroenterol 2004;39:747-753.

9. Seo SW, Hong SJ, Han JP, et al. Accuracy of a scoring system for the differential diagnosis of common gastric subepithelial tumors based on endoscopic ultrasonography. J Dig Dis 2013;14:647-653.

10. Hwang JH, Rulyak SD, Kimmey MB; American Gastroenterological Association Institute. American Gastroenterological Association Institute technical review on the management of gastric subepithelial masses. Gastroenterology 2006;130:2217-2228.

11. Demetri GD, von Mehren M, Antonescu CR, et al. NCCN Task Force report: update on the management of patients with gastrointestinal stromal tumors. J Natl Compr Canc Netw 2010;8 Suppl 2:S1-S41.

12. Menon L, Buscaglia JM. Endoscopic approach to subepithelial lesions. Therap Adv Gastroenterol 2014;7:123-130.

13. Hwang JC, Kim JH, Kim JH, et al. Endoscopic resection for the treatment of gastric subepithelial tumors originated from the muscularis propria layer. Hepatogastroenterology 2009;56:1281-1286.

14. Białek A, Wiechowska-Kozłowska A, Pertkiewicz J, et al. Endoscopic submucosal dissection for treatment of gastric subepithelial tumors (with video). Gastrointest Endosc 2012;75:276-286.

15. Ando N, Goto H, Niwa Y, et al. The diagnosis of GI stromal tumors with EUS-guided fine needle aspiration with immunohistochemical analysis. Gastrointest Endosc 2002;55:37-43.

16. Hoda KM, Rodriguez SA, Faigel DO. EUS-guided sampling of suspected GI stromal tumors. Gastrointest Endosc 2009;69:1218-1223.

17. Sepe PS, Moparty B, Pitman MB, Saltzman JR, Brugge WR. EUS-guided FNA for the diagnosis of GI stromal cell tumors: sensitivity and cytologic yield. Gastrointest Endosc 2009;70:254-261.

18. Mekky MA, Yamao K, Sawaki A, et al. Diagnostic utility of EUS-guided FNA in patients with gastric submucosal tumors. Gastrointest Endosc 2010;71:913-919.

19. Suzuki T, Arai M, Matsumura T, et al. Factors associated with inadequate tissue yield in EUS-FNA for gastric SMT. ISRN Gastroenterol 2011;2011:619128.

20. Akahoshi K, Sumida Y, Matsui N, et al. Preoperative diagnosis of gastrointestinal stromal tumor by endoscopic ultrasound-guided fine needle aspiration. World J Gastroenterol 2007;13:2077-2082.

21. Lee S, Seo DW, Choi JH, et al. Evaluation of the feasibility and efficacy of forward-viewing endoscopic ultrasound. Gut Liver 2015;9:679-684.

22. Larghi A, Fuccio L, Chiarello G, et al. Fine-needle tissue acquisition from subepithelial lesions using a forward-viewing linear echoendoscope. Endoscopy 2014;46:39-45.

23. Eckardt AJ, Adler A, Gomes EM, et al. Endosonographic large-bore biopsy of gastric subepithelial tumors: a prospective multicenter study. Eur J Gastroenterol Hepatol 2012;24:1135-1144.

24. Turhan N, Aydog G, Ozin Y, Cicek B, Kurt M, Oguz D. Endoscopic ultrasonography-guided fine-needle aspiration for diagnosing upper gastrointestinal submucosal lesions: a prospective study of 50 cases. Diagn Cytopathol 2011;39:808-817.

25. Kida M, Araki M, Miyazawa S, et al. Comparison of diagnostic accuracy of endoscopic ultrasound-guided fine-needle aspiration with 22- and 25-gauge needles in the same patients. J Interv Gastroenterol 2011;1:102107.

26. Varadarajulu S, Bang JY, Hebert-Magee S. Assessment of the technical performance of the flexible 19-gauge EUS-FNA needle. Gastrointest 
Endosc 2012;76:336-343.

27. Polkowski M, Larghi A, Weynand B, et al. Learning, techniques, and complications of endoscopic ultrasound (EUS)-guided sampling in gastroenterology: European Society of Gastrointestinal Endoscopy (ESGE) Technical Guideline. Endoscopy 2012;44:190-206.

28. Storch I, Jorda M, Thurer R, et al. Advantage of EUS Trucut biopsy combined with fine-needle aspiration without immediate on-site cytopathologic examination. Gastrointest Endosc 2006;64:505-511.

29. Iwashita T, Yasuda I, Mukai T, et al. Macroscopic on-site quality evaluation of biopsy specimens to improve the diagnostic accuracy during
EUS-guided FNA using a 19-gauge needle for solid lesions: a single-center prospective pilot study (MOSE study). Gastrointest Endosc 2015;81:177-185.

30. Lee JH, Choi KD, Kim MY, et al. Clinical impact of EUS-guided Trucut biopsy results on decision making for patients with gastric subepithelial tumors $\geq 2 \mathrm{~cm}$ in diameter. Gastrointest Endosc 2011;74:1010-1018.

31. Iglesias-Garcia J, Poley JW, Larghi A, et al. Feasibility and yield of a new EUS histology needle: results from a multicenter, pooled, cohort study. Gastrointest Endosc 2011;73:1189-1196. 